\title{
Seismic source studies of non-earthquake natural hazards
}

\author{
Voon Hui Lai, The Australian National University
}

Copyright 2021, SBGf - Sociedade Brasileira de Geofísica.

This paper was prepared for presentation during the $17^{\text {th }}$ International Congress of the Brazilian Geophysical Society held in Rio de Janeiro, Brazil, 8-11 November 2021 (Online Event). Contents of this paper were reviewed by the Technical Committee of the $17^{\text {th }}$ International Congress of the Brazilian Geophysical Society and do not necessarily represent any position of the SBGf, its officers or members. Electronic reproduction or storage of any part of this paper for commercial purposes without the written consent of the Brazilian Geophysical Society is prohibited.

Seismic observations are becoming increasingly important to understand the dynamics behind non-earthquake natural hazards including debris flows, landslides, and volcanic eruptions. Yet, challenging observation environments and the lack of theoretical models hinder the interpretation of observed seismic signals. We will present two examples on the challenges in observing and analyzing natural hazards from seismic data. First, we will demonstrate how a new mechanistic physical model can be applied to understand the high frequency $(>1 \mathrm{~Hz})$ seismic ground motion of debris flows, as observed from the devastating debris flows in Montecito, California on 9 January 2018. The amplitude and frequency characteristics of the seismic data can distinguish debris flows from other seismic sources and enable the estimation of debris-flow speed, width, boulder sizes, and location. Secondly, we will describe the challenges in characterizing volcanic events, especially the source location and mechanism, because of the shallow source depth, significant non double-couple components, and complex velocity structure. Our study of the 2018 Kilauea volcanic eruption found that combining multiple types of geophysical data from broadband seismometers, accelerometers, and infrasound is critical to overcome observational trade-offs and characterize the large M4.7+ seismic events. Seismic moment tensor inversions using near and far field stations were used to resolve the isotropic contribution, which describes the pressurization activity of the magma reservoir, and the faulting behavior of the caldera collapse. Infrasound and particle motion analyses further provide the crucial constraints on source depth and location which are difficult to determine from seismic source inversions alone and can cause bias in the resolved moment tensors.

The above studies have been published in the following journals / open archive:

Lai, V. H., Tsai, V. C., Lamb, M. P., Ulizio, T. P., \& Beer, A. R. (2018). The seismic signature of debris flows: Flow mechanics and early warning at Montecito, California. Geophysical Research Letters, 45(11), 5528-5535. (https://agupubs.onlinelibrary.wiley.com/doi/full/10.1029/2018GL077683)

Lai, V. H., Zhan, Z., Sandanbata, O., Brissaud, Q., \& Miller, M. S. (2021). Inflation and Asymmetric Collapse at Kilauea Summit during the 2018 Eruption from Seismic and Infrasound Analyses.

(https://www.essoar.org/doi/abs/10.1002/essoar.10506637.1) 